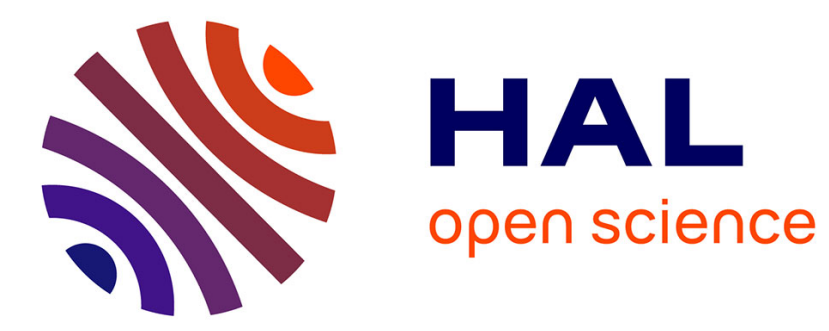

\title{
Conduction and charge storage in Cr-thin SiO2-pSi structures
}

J. Capilla, Gérard Sarrabayrouse

\section{To cite this version:}

J. Capilla, Gérard Sarrabayrouse. Conduction and charge storage in Cr-thin SiO2-pSi structures. Revue de Physique Appliquée, 1984, 19 (4), pp.343-347. 10.1051/rphysap:01984001904034300 . jpa00245202

\section{HAL Id: jpa-00245202 https://hal.science/jpa-00245202}

Submitted on 1 Jan 1984

HAL is a multi-disciplinary open access archive for the deposit and dissemination of scientific research documents, whether they are published or not. The documents may come from teaching and research institutions in France or abroad, or from public or private research centers.
L'archive ouverte pluridisciplinaire HAL, est destinée au dépôt et à la diffusion de documents scientifiques de niveau recherche, publiés ou non, émanant des établissements d'enseignement et de recherche français ou étrangers, des laboratoires publics ou privés. 
Classification

Physics Abstracts

73.60D

\title{
Conduction and charge storage in $\mathrm{Cr}$-thin $\mathrm{SiO}_{2}$-pSi structures
}

\author{
J. Capilla and G. Sarrabayrouse \\ Laboratoire d'Automatique et d'Analyse des Systèmes du C.N.R.S., 7 av. du Colonel Roche, 31400 Toulouse, \\ France
}

(Reçu le 18 novembre 1983, révisé le 13 janvier 1984, accepté le 17 janvier 1984)

\begin{abstract}
Résumé. - Il est montré que les structures $\mathrm{Cr}_{-}-\mathrm{SiO}_{2}-\mathrm{pSi}$ ayant une couche de silice obtenue par oxydation thermique dans un mélange $\mathrm{HCl} / \mathrm{O}_{2} / \mathrm{N}_{2}$ ont des caractéristiques électriques uniformes et reproductibles à faible niveau d'injection. De plus, le phénomène de claquage observé à haut niveau d'injection est associé à un stockage de charges positives dans l'isolant.
\end{abstract}

Abstract. - It is shown that $\mathrm{Cr}-\mathrm{SiO}_{2}$-pSi devices with an $\mathrm{SiO}_{2}$ layer obtained by thermal oxidation in $\mathrm{HCl} / \mathrm{O}_{2} / \mathrm{N}_{2}$ mixture have uniform and reproducible electrical properties at low injection level. Furthermore the breakdown phenomenon observed at high injection level has been associated with a positive charge storage within the insulator.

\section{Introduction.}

The electrical properties of thin oxide layers have been extensively studied and are of great importance for MOS VLSI reliability. This subject has recently gained considerable importance because of new applications of ultra thin $\mathrm{SiO}_{2}$ layers. Indeed EEPROMs and related devices derive advantage from the current flowing through the oxide layer under an electric field ranging between 9 and $13 \mathrm{MV} \mathrm{cm}^{-1}$. The reliability of the device is a critical parameter related to the behaviour of the insulator under such fields.

In particular a breakdown mechanism has been observed for various thickness and oxide preparation parameters associated with negative [1-2] or positive [3-4] charge storage in the insulator and interpreted in terms of avalanche multiplication [5] or electron trapping during current injection [6].

From the results in the literature there is no evidence for a universal behaviour of the silicon dioxide and the growth conditions should certainly control the oxide properties under high electric field. In this paper we present results obtained on $\mathrm{Cr}_{-} \mathrm{SiO}{ }_{2}-\mathrm{Si}(\mathrm{p})$ devices with a $\mathrm{SiO}_{2}$ layer $70-200 \AA$ thick obtained under low partial pressure of oxygen in a $\mathrm{HCl} / \mathrm{O}_{2} / \mathrm{N}_{2}$ mixture. These growth conditions are very well adapted to ultra thin insulating layers and insure a good uniformity of the oxide [7].

First the electrical properties of MIS capacitors at low field will be presented followed by the results about breakdown.

\section{Experimental procedure.}

Metal-oxide-semiconductor capacitors have been fabricated on $5 \Omega \mathrm{cm}$ p-type $\langle 100\rangle$ oriented silicon wafers. After standard cleaning the wafers were oxidized at $1050^{\circ} \mathrm{C}$ in dry $\mathrm{O}_{2}$ during four hours. Windows have been opened by oxide etching prior to reoxidation at $950^{\circ} \mathrm{C}$ in a $\mathrm{N}_{2} / \mathrm{O}_{2}(10 \%) / \mathrm{HCl}(0,2 \%)$ mixture respectively during $10,15,30,60 \mathrm{~min}$. Then $3000 \AA$ thick square chromium dots have been evaporated onto the oxide. No annealing has been performed in order to avoid contamination of the oxide layer by metallic impurities. The thickness of the oxide layer measured by the $C-V$ technics has been found to be $185 \AA, 130 \AA, 90 \AA$ and $72 \AA$.

Measurements have been made on fifteen samples of each batch using the experimental apparatus shown on figure 1. For each sample current-voltage $(I-V)$ followed by high $(1 \mathrm{MHz})$ and low $(1 \mathrm{kHz})$ frequency capacitance measurements. Then the $I-V$ curve has been again recorded up to breakdown. For some samples pulse stress has been applied followed by static $I-V$ and $C-V$ measurements.

\section{Experimental results and discussion.}

3.1 LOW LEVEL CURRENT INJECTION. - Typical $J$ - $V$ curves corresponding to electron injection from the metal are shown on figure 2 for some samples.

At low level the current follows a Fowler-Nordheim Law [8]. This can be shown first when the electric field $E_{\mathrm{ox}}$ corresponding to a given current is computed from the applied voltage by solving Poisson and Gauss 


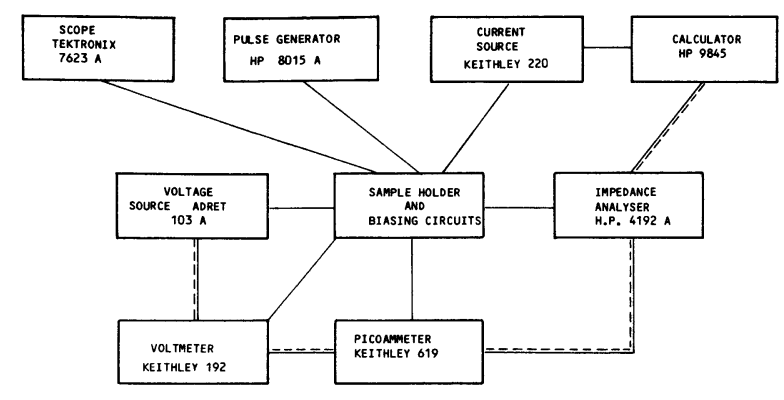

Fig. 1. - Experimental apparatus.

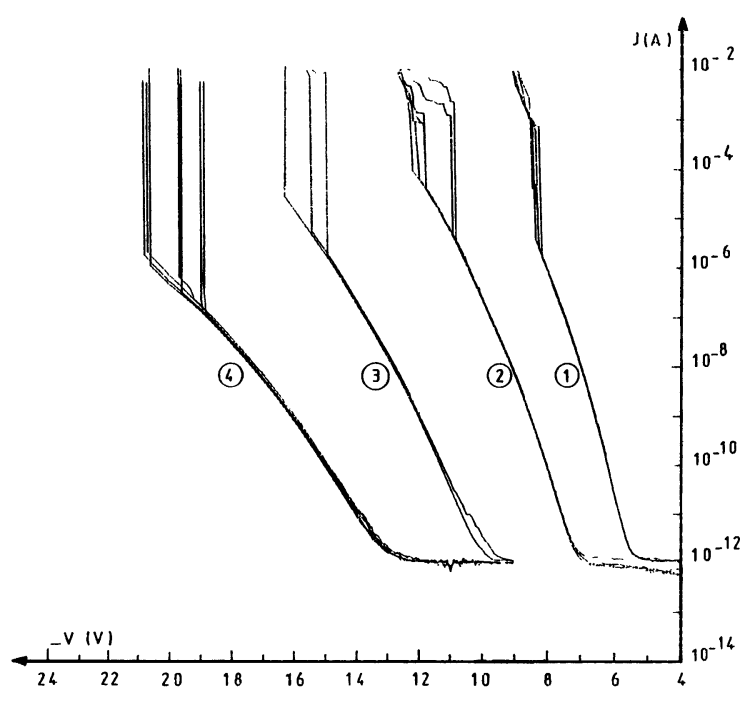

Fig. 2. - Current-voltage curve. $1: d_{\mathrm{ox}}=72 \AA ; 2: d_{\mathrm{ox}}=90 \AA$; $3: d_{\mathrm{ox}}=130 \AA ; 4: d_{\mathrm{ox}}=185 \AA$ device area $: 9 \times 10^{4}(\mu \mathrm{m})^{2}$.

equations assuming a metal to semiconductor barrier height equal to $-0.06 \mathrm{eV}$ [9]. As shown on figure 3 this field is independent of the insulator thickness $d_{\mathrm{ox}}$ in agreement with Fowler-Nordheim injection. Second if we plot the $J-V$ curve in a Fowler-Nordheim graph the curve is linear within the whole current range (Fig. 4). Assuming an electron effective mass in silica equal to $0.5[10]$ the metal to insulator barrier heigh $\varnothing_{m}$ can be calculated from the slope of this curve. Results are presented in table I and show a satisfactory agreement with results obtained by photoelectric measurements [11].

Table I.

$\begin{array}{rcc}d_{\mathrm{ox}}(\AA) & k_{2}\left(\mathrm{~V} \mathrm{~cm}^{-1}\right) & \varnothing_{\mathrm{m}}(\mathrm{eV}) \\ \overline{72} & 2.40 \times 10^{8} & -2.90 \\ 90 & 2.21 \times 10^{8} & 2.76 \\ 130 & 2.44 \times 10^{8} & 2.94 \\ 185 & 2.13 \times 10^{8} & 2.69 \\ & J=\mathrm{A} k_{1} \varepsilon_{\mathrm{ox}}^{2} \exp \left(-k_{2} / \varepsilon_{\mathrm{ox}}\right) \\ & \varnothing_{\mathrm{m}}=\left(\frac{k_{2}}{4.83 \times 10^{7}}\right)^{2 / 3} .\end{array}$

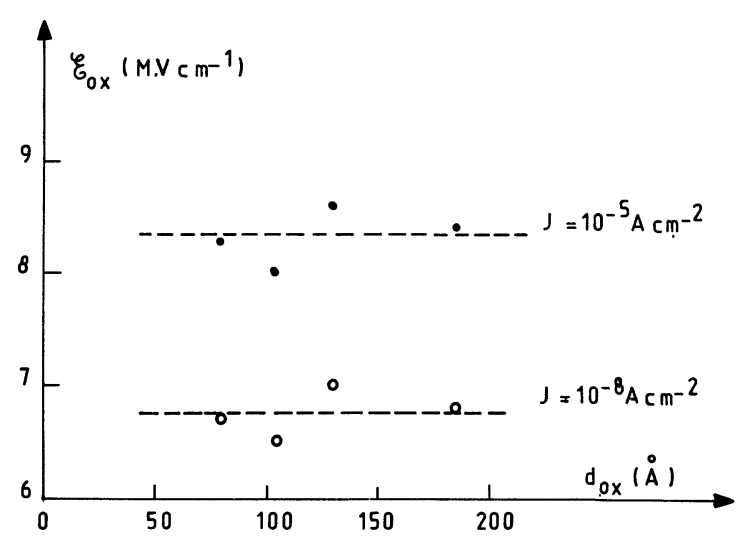

Fig. 3. - Electrical field versus oxide thickness for two values of the current.

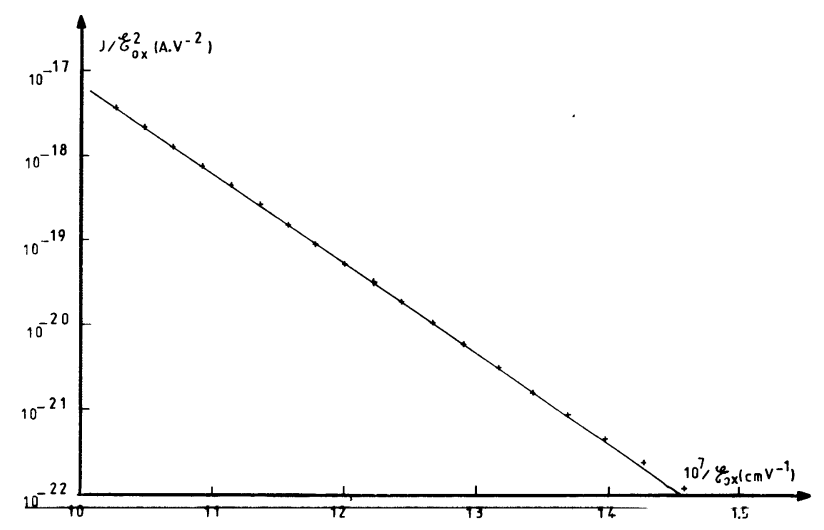

Fig. 4. - Current versus electric field in a Fowler-Nordheim graph $d_{\mathrm{ox}}=130 \AA$.

This behaviour has been found very reproducible from device to device and stable after three monthes without applied bias although the devices were not passivated. This reproduce ability together with the proportionality observed for thicknesses lower than $100 \AA$ between the current and the device area (Fig. 5) show that the insulating layer is certainly uniform and that the conduction does not take place on local sites at least before breakdown. Furthermore no instability has been observed at low level [12].

A deviation from the current proportionality to the device area has been observed for oxide layers thicker than $100 \AA$. Probably this can be due to a thinning of the oxide near the edge of the isolation oxide as already observed experimentally [13] and predicted theoretically [14]. It should, be noticed for instance that with a $130 \AA(185 \AA)$ thick oxide layer a $10 \%$ thinning of this layer over a peripheric region with area $10 \%(1 \%)$ of the total area results in a current proportional to the perimeter of the device (slope equal to one in Fig. 5).

3.2 Capacitance-voltage curve. - Typical high and low frequency capacitance-voltage curves of the above mentionned devices are shown on figure 6 . The 


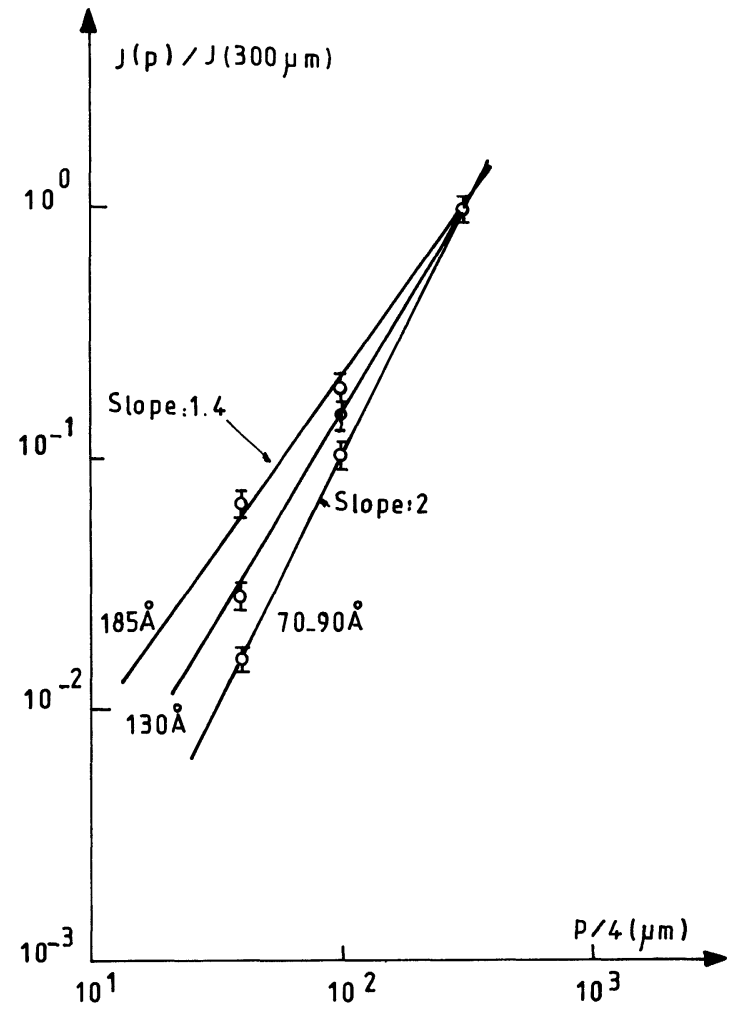

Fig. 5. - Dependence of the current upon device perimeter $p$.

thickness of the oxide layer has been evaluated from the maximum of the capacitance curve. A small spreading (lower than $7 \%$ ) of the capacitance value has been observed from device to device. This has not to be correlated with a possible spreading of the thickness because of the good reproducibility of the current but rather to experimental difficulties associated with probing.
The surface state density has been extracted from the $C-V$ measurements. A typical energetic distribution of the surface states is shown of figure 7 . The density peak is in the range $1-4 \times 10^{11} \mathrm{~cm}^{-2} \mathrm{eV}^{-1}$ depending upon the thickness, which is not very high for unannealed samples. Furthermore the shape of the peak and its location near the valence band is in agreement with results obtained previously on MIS tunnel diodes [15].

3. 3 High LEVEL CURRENT INJECTION. - As shown on figure 2 when the current is increased beyond a threshold value the device breaks definitely. No selfhealing breakdown has been observed during pulse measurement. The electric field at breakdown has been found to depend upon the oxide thickness as shown on figure 8 and follows approximately a $d_{\mathrm{ox}}^{-\gamma}$ law with $\gamma \approx 0.53$. Different values have been obtained in the literature ranging between 0.21 [16] to 0.66 [17] for $\mathrm{SiO}_{2}$ layers. A value of 0.5 is predicted by the simplest breakdown theory based on avalanche ionization in the oxide layer [18]. In order to investigate more deeply the origin of the breakdown we have made pulse measurements with voltage pulse amplitude $V_{\mathrm{p}}$ larger than the static breakdown voltage value and $200 \mu \mathrm{s}$ long. After each single pulse low level $J-V$ and high frequency $C-V$ curves have been recorded.

Results are shown on figures 9 and 10 in the case of a $130 \AA$ thick oxide layer.

Both figures show the creation of a positive charge in the oxide layer, the influence of this charge being greater on the $C-V$ curve than on the $I-V$ one.

This fact can be interpreted through a localization of the charge very near the $\mathrm{SiO}_{2}-\mathrm{Si}$ interface in accordance with a significative increase of the interface state density as shown in figure 11 .

Even if the breakdown appears to be related to the creation of a positive space charge possibly at the origin of an impact ionisation mechanism this last phenomenon is not at the origin of the positive charge.

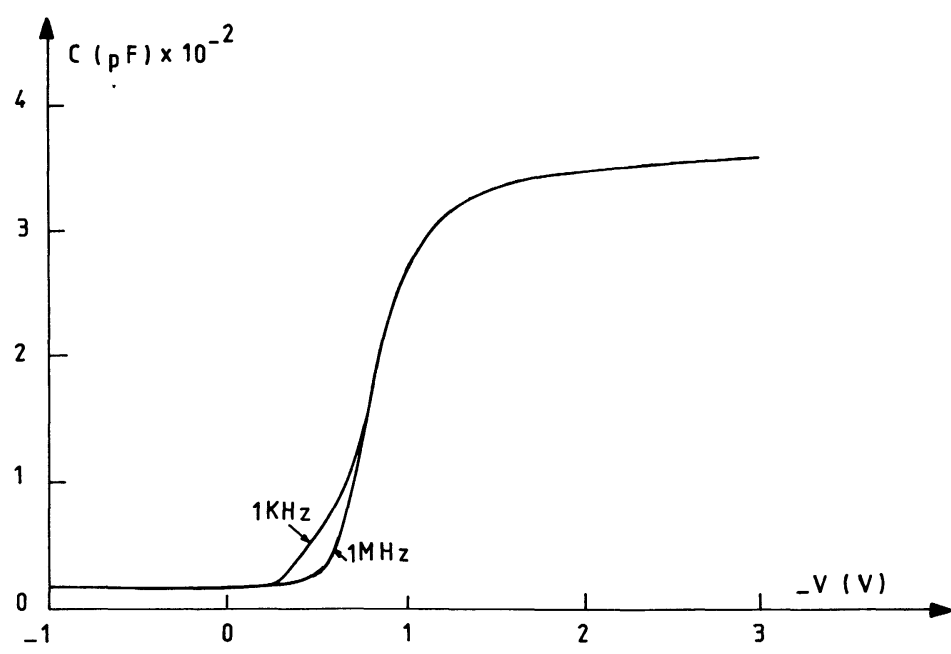

Fig. 6. - Typical capacitance-voltage curve $d_{\mathrm{ox}}=90 \AA$. 


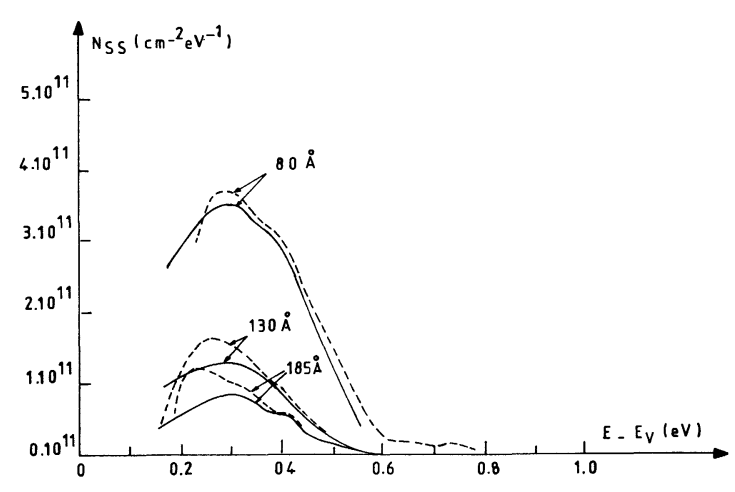

Fig. 7. - Energetic distribution of interface states as a function of the oxide thickness $d_{\mathrm{ox}}$ obtained from : — difference between low and high frequency capacitance --. Terman's Method.

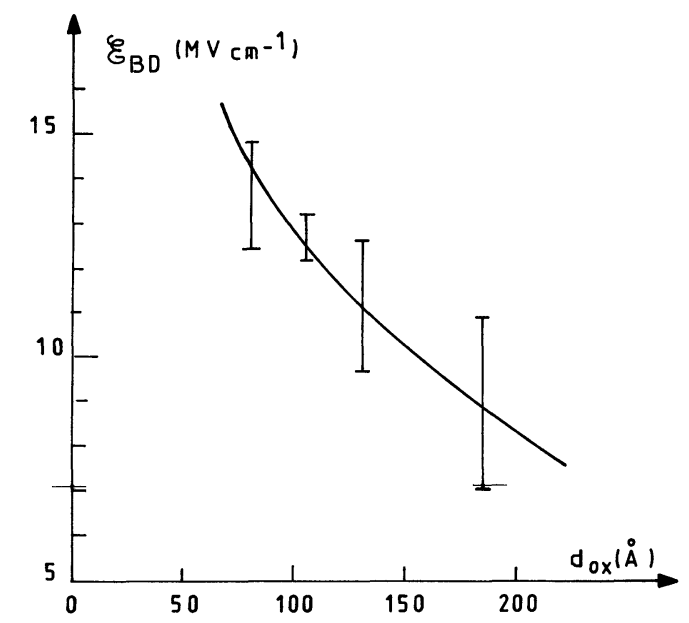

Fig. 8. - Dependence of the electric field at breakdown $\varepsilon_{\mathrm{BD}}$ upon the oxide layer thickness.

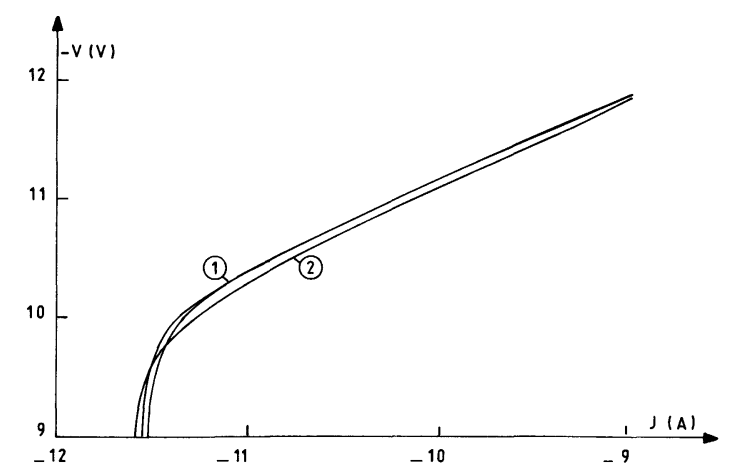

Fig. 9. - Low level current-voltage curve before and after single pulse stress. $1:$ initial and after $V_{\mathrm{p}}=15 \mathrm{~V} ; 2:$ after $V_{\mathrm{p}}=20 \mathrm{~V}$.

Indeed constant current stresses have been performed at a current level two decades lower than the current level at breakdown and also a positive charge appears with a very long time constant a shown on figure 12.

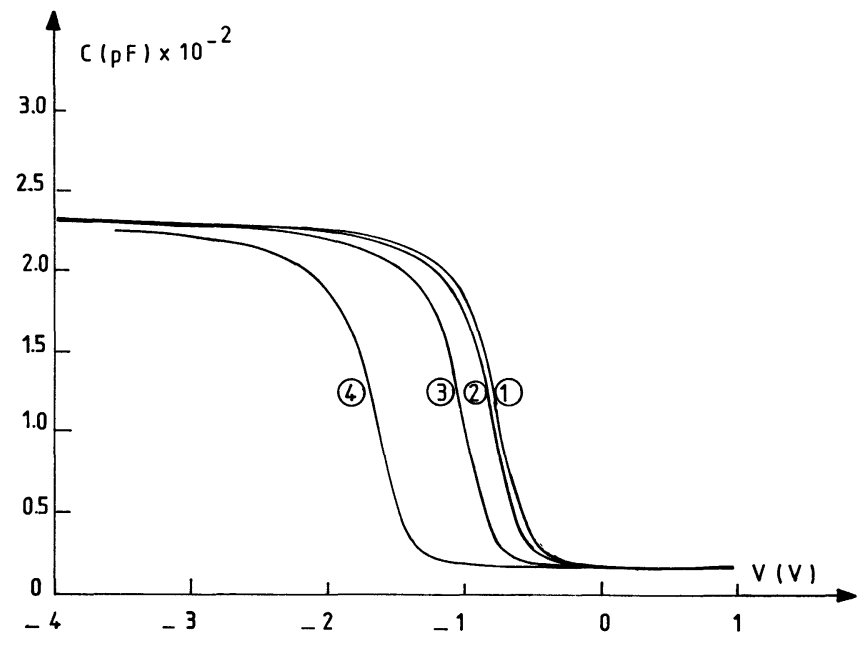

Fig. 10. - Capacitance-voltage curve before and after single pulse stress. $1:$ initial; $2:$ after $V_{\mathrm{p}}=15 \mathrm{~V} ; 3:$ after $V_{\mathrm{p}}=20 \mathrm{~V} ; 4:$ after $V_{\mathrm{p}}=25 \mathrm{~V}$.

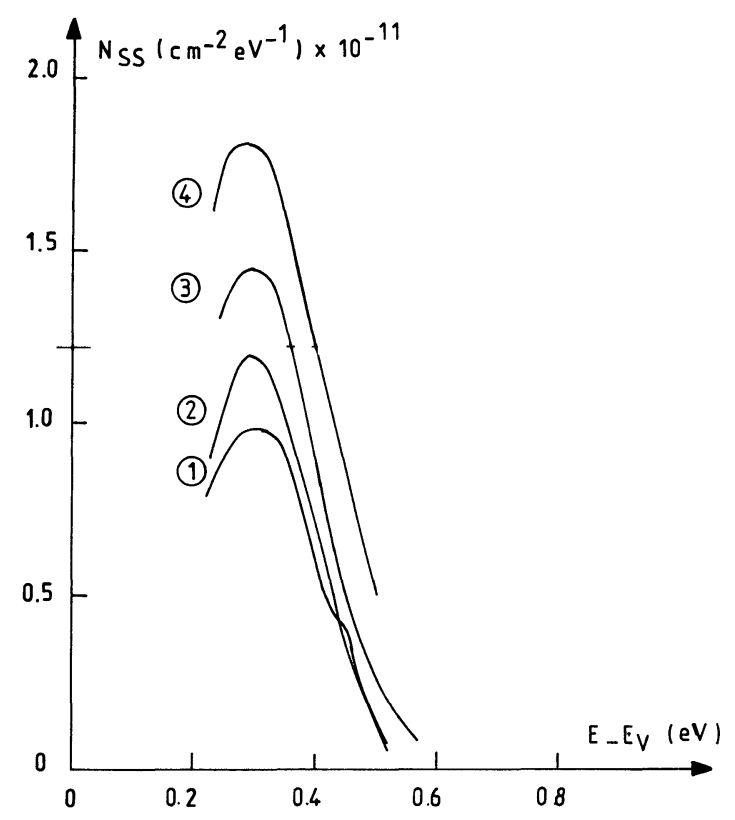

Fig. 11. - Influence of a single voltage pulse on the surface state density. Experimental conditions are the same as for figure 10 .

\section{Summary.}

We have shown that Metal-70-200 $\AA \mathrm{SiO}_{2}$-Si diodes with oxide obtained at high temperature in partial pressure of $\mathrm{O}_{2}$ and $\mathrm{HCl}$ have good electrical properties with stable and reproducible $J-V$ curves following the Fowler-Nordheim law.

A breakdown mechanism related to a positive charge build-up near the $\mathrm{SiO}_{2}-\mathrm{Si}$ interface has been shown. The origin of this charging is not well understood and is not due to impact ionization even if this last mechanism can initiate the breakdown once the charge is sufficiently high. 


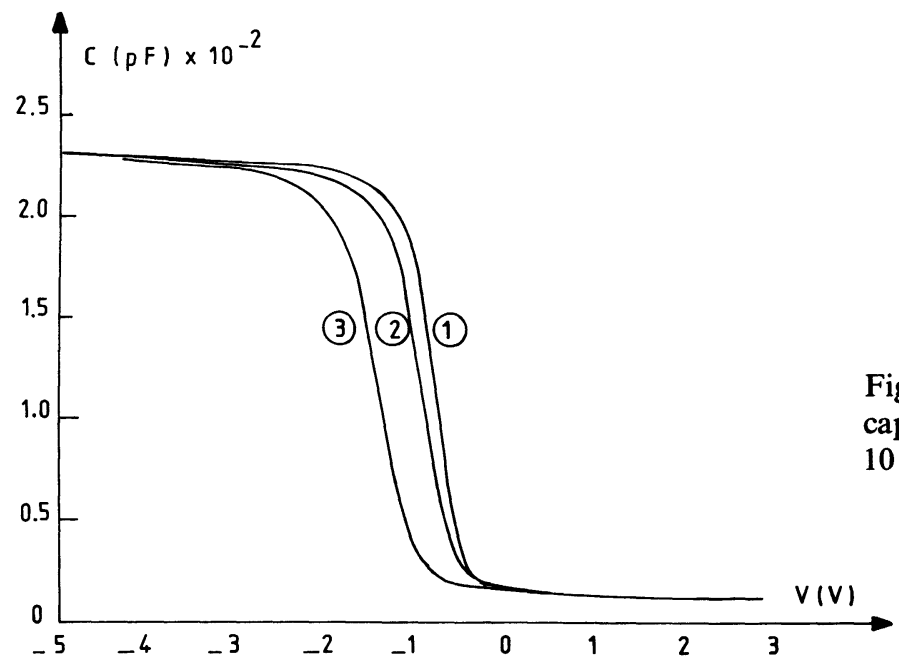

\section{References}

[1] Harari, E., Appl. Phys. Letters 30 no 11 (1977) 601. [2] Liang, M. S. et al., International Electron Device Meeting, p. 50.

[3] Schatzkes, M. et al., J. Appl. Phys. 47 no 7 (1976) 3192.

[4] Maserjian, J. et al., J. Vac. Sc. Technol. $20 \mathrm{n}^{\circ} 3$ (1982) 743.

[5] Distephano, T. H. et al., Appl. Phys. Lett. 25 no 12 (1974) 685.

[6] Solomon, P., J. Appl. Phys. 48 no 9 (1977) 3843.

[7] Capilla, J. et al., to be published.

[8] Lenzlinger, M. et al., J. Appl. Phys. 40 (1969) 278.

[9] KAR, S., Solid State Electron. 18 (1975) 169.

[10] Weinberg, Z. A., J. Appl. Phys. 53 no 7 (1982) 5052.
Fig. 12. - Influence of a constant current stress on the capacitance-voltage curve. 1 : initial; $2:$ after $J=10^{-9}$ A$10 \mathrm{~min} ; 3:$ after $J=10^{-7} \mathrm{~A}-5 \mathrm{~min} ; d_{\mathrm{ox}}=130 \AA$.
[11] Sommer, H., Photoemissive Materials (J. Wiley, NewYork).

[12] Osburn, C. M. et al., J. Electrochem. Soc. 119 no 5 (1972) 603.

[13] SHENG, T. T. et al., J. Electrochem. Soc. 125 no 3 (1978) 432.

[14] Wilson, L. O., J. Electrochem. Soc. 129 no 4 (1982) 831.

[15] Kar, S. and Dahlke, W. E., Appl. Phys. Lett. 18 no 9 (1971) 401.

[16] Osburn, C. M. et al., J. Electrochem. Soc. 119, no 5 (1972) 597.

[17] Pratt, I. M., Solid State Technol. (1969) 49.

[18] Forlani, F. et al., Phys. Status Solidi 4 (1964) 311. 